\title{
ARTÍCULOS
}

\section{CONFLICTO Y GUERRA EN EL CARIBE. PAPEL DESEMPEÑADO POR LAS MILICIAS DE INDIOS FRENTE AL INTENTO DE INVASIÓN BRITÁNICA A SANTIAGO DE CUBA (1739-1748).}

\author{
Lilyam Padrón Reyes \\ Universidad de Cádiz \\ lilyam.padron@uca.es
}

Resumen: En el presente artículo estudiaremos las causas y el desenlace de la victoria hispana sobre la armada inglesa del almirante Edward Vernon durante el sitio a la ciudad de Santiago de Cuba (1739-1741) en medio de la guerra del Asiento. Prestaremos especial interés en nuestro análisis al accionar de las milicias de indios de los pueblos de San Luis de Los Caneyes y San Pablo de Jiguaní, que junto a otros grupos armados llevarían un peso decisivo en expulsar al enemigo, y salvaguardar los intereses del imperio español en tierras cubanas.

Palabras clave: Guerras coloniales, imperio español, armada inglesa, milicias, indios, Edad Moderna.

Tittle: CONFLICT AND WAR IN THE CARIBBEAN. ROLE PERFORMED BY THE MILITIAS OF INDIANS AGAINST THE ATTEMPT OF THE BRITISH INVASION TO SANTIAGO DE CUBA (1739-1748).

Abstract: In this article we will study the causes and the outcome of the Hispanic victory over the English Navy of Admiral Edward Vernon during the siege to the city of Santiago de Cuba (1739-1741) in the middle of the War of the Seat. We will pay special attention to our analysis of the actions of the Indian militias of the towns of San Luis de Los Caneyes and San Pablo de Jiguaní, which along with other armed groups would carry a decisive weight in expelling the enemy, and safeguarding the interests of the Spanish empire in Cuban lands.

Keywords: Colonial wars, Spanish empire, British Navy, militias, Indians, Early Modern Age.

\section{Introducción}

A lo largo de toda la época moderna, el espacio Caribe representaría un mundo en miniatura de imperios marítimos en competencia. Con el advenimiento de la firma del Tratado de Utrecht, finalizaría el conflicto europeo abierto tras la guerra de sucesión española, donde la realidad demostraría la superioridad naval británica. Con su firma se abriría un nuevo ciclo al comercio inglés que, en consonancia,

Recibido: 28-08-2019

Aceptado: 02-09-2019

Cómo citar este artículo: PADRÓN REYES, Lilyam. Conflicto y guerra en el Caribe. Papel desempeñado por las milicias de indios frente al intento de invasión británica a Santiago de Cuba (1739-1748). Naveg@mérica. Revista electrónica editada por la Asociación Española de Americanistas [en línea]. 2020, n. 24. Disponible en: <http://revistas.um.es/navegamerica>. [Consulta: Fecha de consulta]. ISSN 1989-211X. 
reafirmaría por toda Europa su fortaleza comercial, naval y marítima frente al resto de potencias, especialmente España y Francia.

En este contexto, las Indias Occidentales, tan lejanas geográficamente pero tan cercanas políticamente a su metrópoli británica no solo significarían una base comercial transcontinental, sino también un espacio natural del poder imperial en la gestión y el perfeccionamiento de sus mecanismos de expansión ultramarina. La localización geoestratégica de Jamaica le situaría como un enclave fundamental a lo largo del siglo XVIII, y especialmente durante la guerra del Asiento o de la Oreja de Jenkins (1739-1748) en el tráfico de información (prisioneros, defensas, ideas y personas), con el objetivo de controlar los planes estratégicos de sus rivales españoles y franceses, y articular nuevas estrategias que permitiesen fortalecer su poderío marítimo sobre el mundo atlántico ${ }^{1}$.

La cercanía geográfica del puerto de Santiago de Cuba con Jamaica (KingstonPort Royal) influiría notablemente en que, desde los primeros tiempos, sus autoridades y agentes utilizasen los vínculos directos e indirectos para reconocer la posición y el alcance de los planes estratégicos de ambos imperios. Acudimos a la época en que los conflictos del Caribe ya no serían del quehacer de corsarios y piratas, sino competencia directa de las armadas y los ejércitos de las potencias europeas con intereses coloniales en el espacio americano ${ }^{2}$.

Al estudio de los conflictos modernos en el Caribe, numerosos especialistas han dedicado sus esfuerzos desde múltiples enfoques y metodologías ${ }^{3}$. Su amplio marco de circulaciones y transferencias es una fuente inagotable para profundizar en la compleja interrelación atlántica, que desde la historia económica y social trascendería los límites de sus fronteras marítimas, y participaría activamente de la era moderna europea.

En el texto, nos proponemos abordar y contextualizar la participación de las milicias, como un fiel reflejo de la situación social reinante entre los distintos grupos del régimen colonial hispano y sus relaciones políticas. De cara a un orden militar, que intentaría conciliar intereses y carestías en torno a la necesidad de una amplia participación popular que consiguiera fortalecer las estructuras político-sociales en sus territorios, y salvaguardar la soberanía hispana frente al resto de potencias externas.

\footnotetext{
${ }^{1}$ BEAEZA MARTIN, Ascensión. Las argucias de la guerra: El gobernador Cajigal y el asedio inglés desde Guantánamo en 1741. Temas Americanistas. 2007, n. 19, pp. 50-69.

2 PORTUONDO ZÚÑIGA, Olga. Una derrota británica en Cuba. Santiago de Cuba: Editorial Oriente, 2015, p. 35.

3 AMOR MARTíN, Francisco de Asís. Crónica del combate naval de La Habana de 1748. Naveg@mérica. Revista electrónica editada por la Asociación Española de Americanistas. 2018, n. 20; CERDÁ CRESPO, Jorge. Conflictos coloniales: la Guerra de los Nueve Años 1739-1748. Alicante: Servicio de Publicaciones de la Universidad de Alicante, 2010; PARES, Richard. War and Trade in the West Indies, 1739-1763. Londres: Oxford University, 1936; HANSEN, Jonathan M. Guantánamo. An American History. Nueva York: Hill and Wang, 2011; HARDING, Richard. Amphibious warfare in the eighteenth century. The British Expedition to the West Indies, 1740-1742. Woodbridge: Boydell \& Brewer Inc. 1991; ZAPATERO, Juan Manuel. La guerra del Caribe en el siglo XVIII. Madrid: Servicio Histórico Militar, 1990.
} 
A través de un nutrido abanico de fuentes bibliográficas y documentales, tomando con especial interés los numerosos fondos del Archivo General de Indias y el Archivo Nacional de Cuba intentaremos contextualizar un punto de vista crítico de la temática con un carácter histórico-documental. A partir del análisis de la documentación primaria pretendemos comprender la realidad colonial según los discursos oficiales contenidos en sus dos visiones: hispana y anglosajona.

El presente resultado de investigación constituye solo un acercamiento al tema, que, por su complejidad y dispersión de fuentes requiere de sucesivas y sistemáticas aproximaciones. De igual forma, pretendemos con nuestro trabajo contribuir a una nueva realidad del espacio colonial cubano en medio del entramado imperial hispano del siglo XVIII, de cara a una política oficial donde todos sus actores estarán llamados a jugar un papel en la defensa del imperio español.

\section{Santiago de Cuba en la órbita de Edward Vernon, 1739-1741}

Si bien a comienzos del siglo XVIII, Inglaterra conseguiría una importante victoria con la firma del Tratado de Utrech (1713), que le aseguraría inmejorables dividendos comerciales a través del monopolio del asiento, y le abría las puertas al ansiado mercado americano, estas no serían condiciones suficientes para satisfacer la ambición política y económica de su burguesía comercial y representantes oficiales. Unido a ello, la compleja relación de equilibrios europeos sería motivo de que la política exterior de España diese un fuerte impulso en contener los intereses británicos, a partir del nombramiento de José Patiño, como intendente general de Marina, intentando centrarse en el espacio americano, y en especial en el Caribe, como zona vulnerable frente a un ataque de Inglaterra ${ }^{4}$.

En 1738, finalmente se rompería la paz diplomática entre España e Inglaterra, desencadenándose la llamada "guerra de la Oreja de Jenkins" . En octubre de 1739, el primer ministro británico Robert Walpole declararía abiertamente la guerra, bajo los términos de:

"[...] y por este medio declaramos nuestra voluntad y requerimos de nuestros generales y jefes de nuestras fuerzas, nuestros comisionados ejecutivos de la oficina del alto almirantazgo de Gran Bretaña, nuestros Lugartenientes de algunos de nuestros países, gobernadores de nuestros fuertes y guarniciones, y todos los otros oficiales y soldados bajo ellos, por mar y tierra, para hacer, y ejecutar todos los actos de hostilidad en la prosecución de esta guerra contra dicho Rey de España, sus vasallos, y súbditos, y se opongan a sus tentativas; y por este medio ordenamos, tanto a nuestros propios Súbditos, como advertimos a cualquier otra persona, de la nación que sea, no transportar, o llevar soldados, armas, pólvora, municiones u otra mercancía de contrabando, a cualquiera de los territorios,

\footnotetext{
${ }^{4}$ MARRERO, Leví. Cuba economía y sociedad. T. IV. Madrid: Editorial Playor, 1975, p. 80.

${ }^{5}$ Su nombre viene dado del capitán mercante inglés Robert Jenkins que, en 1738, llevaría a la Cámara de los Comunes el relato del drama vivido a raíz de haber sido apresado por corsarios cubanos en el norte de Cuba, y donde le había sido mutilada una oreja; la cual conservaba en un cofre de ébano y marfil, y llevaba a su exposición como prueba de la crueldad con que obraban los corsarios españoles en abierta provocación a la Corona británica; vid. CERDÁ CRESPO, Jorge. Conflictos coloniales. Op. cit.
} 
tierras, plantaciones, o países del dicho rey de España; declarando, que cualquier barco o nave puede ser apresada, si transporta o lleva soldados, armas, pólvora, municiones, u otra mercancía de contrabando, a cualquiera de los territorios, tierras, plantaciones o países de dicho Rey de España. El mismo será ocupado y puede ser condenado legítima y legalmente. Dado en nuestra Corte de Kingston el día diecinueve de octubre, 1739 del décimo tercer año de nuestro reinado"6.

Atendiendo a su estrategia los ingleses evaluarían a Cuba como la llave necesaria para controlar todo el comercio atlántico del imperio español ${ }^{7}$. Según declaración de Sir William Poultney a Vernon, la trascendencia era tal que "cuando tomarán la isla el mundo entero no sería capaz de arrebatársela"8.

Siendo así, no tardaría en romperse el equilibrio de poderes con el inicio de la guerra de la Oreja de Jenkins o guerra del Asiento, en 1739, inaugurándose un nuevo período de conflictos para la soberanía española en América. En correspondencia con el nuevo escenario, la Corona hispana no demoraría en poner sobre alerta sus principales plazas en cada uno de sus territorios, y en especial a sus autoridades, a través de una real cédula donde les prevenían de las hostilidades contra Inglaterra, y las acciones a seguir bajo los términos de:

"[...] teniendo en cuenta mi real determinación, la hagan publicar en sus distritos en la forma más acostumbrada, y como haya sido práctica, y estilo en caso semejantes, y que arreglados a ella, celen, atiendan, y cuiden del resguardo, y defensa de las plazas, provincias, puertos, y costas sujetos a su jurisdicción, previniendo, armando, y aprontando las tropas regladas, que tienen destinadas de dotación para su custodia, y a todas las milicias del país, tanto de infantería, como de caballería, que deben estar reseñadas y alistadas para las ocasiones de insultos de enemigos, en cumplimiento y observancia de lo que prescriben las Leyes de indias, y está mandado por posteriores reales ordenes expedidas en este punto"'.

En el análisis de los sitios estratégicos por las fuerzas británicas, La Habana y Cartagena de Indias, jugarían un papel esencial como ejes del comercio indiano. En cambio, la ciudad de Santiago de Cuba ocuparía un lugar secundario, al encontrarse marginada del circuito mercantil ${ }^{10}$. No obstante, el gobernador de Santiago de Cuba, Francisco Cajigal de la Vega, también sería alertado desde 1739, en reforzar las defensas de la plaza de Cuba ante las informaciones particulares de un inminente asalto como parte de la estrategia trazada por el almirante Edward Vernon en relación a su proximidad geográfica con Jamaica, y la idea de que una vez consiguiesen tomar y neutralizar la importante base de operaciones del corso criollo,

\footnotetext{
${ }_{7}^{6}$ PORTUONDO ZÚÑIGA, Olga. Una derrota británica... Op. cit., p. 86.

7 Cfr. RIVAS IBAÑEZ, Ignacio. Mobilizing resources for war: The British and Spanish intelligence systems during the War of Jenkins' ear (1739-1744) [tesis doctoral inédita]. Londres: University College, 2008.

${ }^{8}$ MARRERO, Leví. Cuba economía... Op. cit., t. IV, p. 92.

${ }^{9}$ Archivo Nacional de Cuba (en adelante ANC), Asuntos políticos, leg. 1, exp. 24. Real cédula para que los virreyes, gobernadores, capitanes generales y ministros de los dominios de América hagan publicar la declaración de guerra contra Inglaterra, y ejecuten lo demás que se expresa. Buen Retiro, 5 de diciembre de 1739.

${ }^{10}$ PORTUONDO ZÚÑIIGA, Olga. Una derrota británica... Op. cit., p. 127.
} 
avanzarían sobre el resto de la isla, y finalmente se apoderarían de La Habana ${ }^{11}$. Para el mando inglés, apoderarse del puerto habanero representaría su gran objetivo, atendiendo a la concepción de que significaba controlar la "llave del comercio de Indias en América"12.

Con arreglo al plan de defensa previsto, el reparo de sus fortificaciones sería tema prioritario, tomando en cuenta la indefensión que presentaba la ciudad a causa del pésimo estado de sus principales defensas. Atendiendo a ello, las mejoras realizadas por Cajigal, bajo la supervisión del ingeniero militar Francisco de Angle ascenderían a un monto de 101611 pesos, con especial atención al reforzamiento del castillo del Morro, batería La Estrella, y el fuerte de Aguadores ${ }^{13}$. Los arreglos tomarían en cuenta la ubicación estratégica de numerosas piezas de artillería en los diferentes enclaves con el objetivo de que, en caso de un ataque directo del enemigo, ya fuese por mar o tierra, estuviesen en condiciones de defender los principales accesos e impedir el avance al interior de la ciudad ${ }^{14}$.

Bajo las órdenes de Vernon, el contralmirante Chaloner Ogle, el general Thomas Wentworth y el general Guise, con cerca de ocho mil hombres pretendían tomar por asalto la ciudad de Santiago de Cuba. Aunque una vez reconocidos los trabajos de refuerzos del entorno de su bahía, y vistas las tropas aprestadas, los ingleses optarían por cambiar el rumbo de su desembarco a la bahía contigua de Guantánamo $^{15}$, con la intención de estudiar mejor el terreno, y ejecutar el ataque a la capital suroriental de manera simultánea por mar y tierra tomando por sorpresa sus principales defensas.

\footnotetext{
${ }^{11}$ Vid. HERNÁNDEZ LÓPEZ, Ignacio. La defensa de Santiago de Cuba al ataque de Vernon de 1741: Principios de fortificación para la guerra en el Caribe. Anuario de Estudios Americanos. 2019, vol. 76, n. 1, pp. 177-207.

${ }^{12}$ MARRERO, Leví. Cuba economía... Op. cit., t. IV, p. 92.

${ }^{13}$ Ibídem.

${ }_{15}^{14}$ PORTUONDO ZÚÑIGA, Olga. Una derrota británica... Op. cit., p. 116.

${ }^{15}$ La bahía de Guantánamo se encontraba separada por tierra en apenas unos 100 kilómetros de la capital departamental; vid. PORTUONDO ZÚÑIGA, Olga. Santiago de Cuba desde su fundación hasta la guerra de los diez años. Santiago de Cuba: Editorial Oriente, 1989, pp. 69-70.
} 


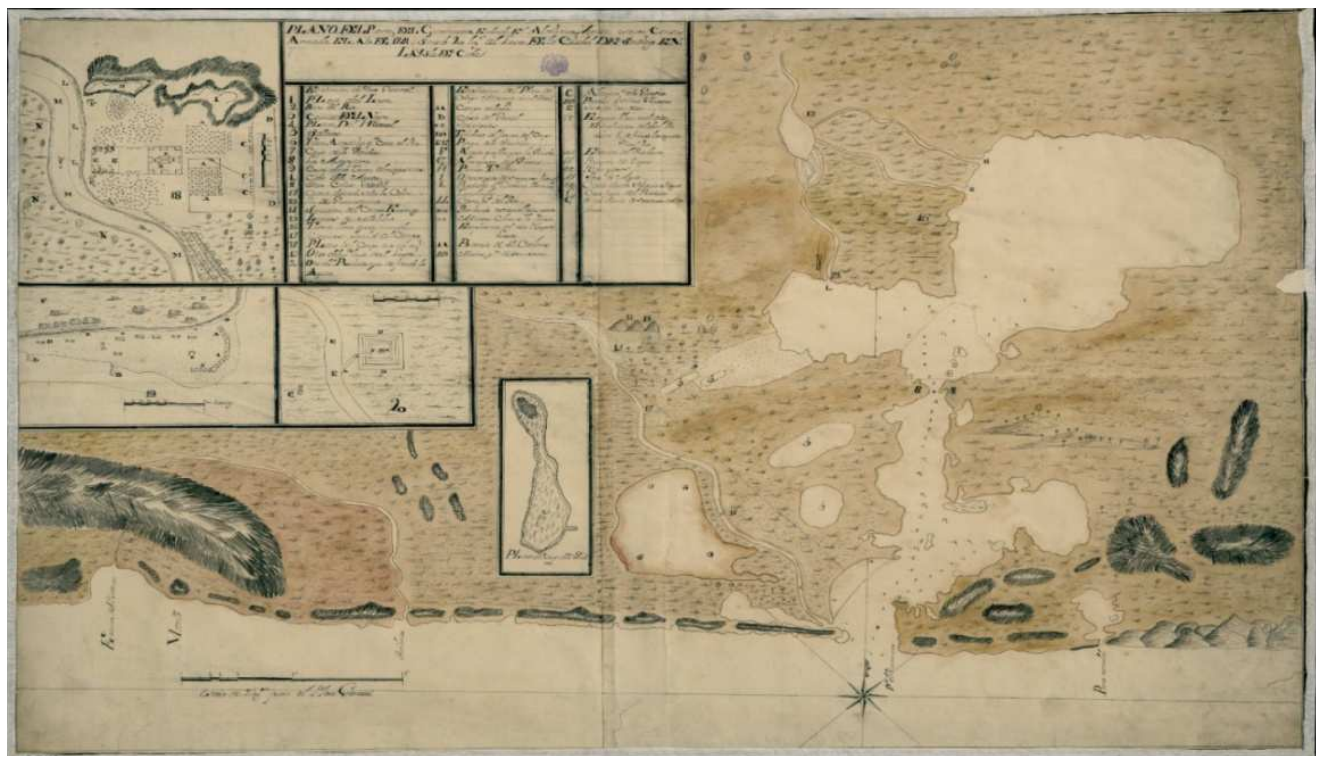

Fig. 1: Plano del puerto de Guantánamo (1741). Fuente: Biblioteca Nacional de España, Material cartográfico manuscrito, Guantánamo (Cuba), mapas militares- 1741.

Frente a tales propósitos el gobernador Cajigal de la Vega, en su estrategia conseguiría reunir la mayor cantidad de tropas regulares y de milicias, que actuarían como elemento determinante en impedir la agresión británica directa. Nuevamente se daría una gran importancia a la convocatoria de los vecinos, práctica que se continuaría en la gestión ilustrada del ministro Campillo, fiel continuador de la obra de su antecesor José Patiño, y que pondría de manifiesto la necesidad de contar con los pobladores americanos en la defensa ${ }^{16}$.

Ante la demora en la llegada de refuerzos desde La Habana, se tomaría la determinación de recurrir al apoyo inestimable de las fuerzas de milicias, con un papel determinante por sus habilidades en ocupar y estar alerta sobre los puntos reforzados a sotavento y barlovento de la costa. Ante tales acontecimientos, el presidio santiaguero estaría distribuido en cinco compañías regulares y cuatro de refuerzo conformadas por más de doscientos hombres; junto a las de milicias distribuidas en dos de infantería y dos de caballería, organizadas de acuerdo a su condición social en blancos, naturales, negros y pardos, engrosarían las fuerzas que harán frente a la amenaza británica ${ }^{17}$.

Llegado el momento de la convocatoria oficial las fuerzas de las poblaciones de Los Caneyes y Jiguaní, acudirán prestas al llamado de las autoridades locales para ocupar posiciones en los distintos puntos defensivos. En particular, las milicias de Los Caneyes con tradición en la defensa de los fuertes de Jurágua Grande y Chico

\footnotetext{
${ }^{16} \mathrm{Y}$ al respecto expresaría que: "[...] Y me manda S.M. a V.S. confiar de la acertada conducta del valor de su tropa y milicias del país, y de la lealtad, y amor de esos vasallos que habrá procurado y continuarán por todos los medios posibles frustrar los intentos de los enemigos, castigar su osadía, y dejarles con escarmiento, para que no se arrojen temerariamente a semejantes insultos"; ANC, Asuntos políticos, leg. 1, exp. 39. Carta del ministro Campillo al gobernador Francisco Cajigal de la Vega. Madrid, 18 de diciembre de 1741. Vid. BAUDOT MONROY, María (ed.). El Estado en Guerra. Expediciones navales españolas en el siglo XVIII. Madrid: Ediciones Polifemo, 2014.

${ }^{17}$ PORTUONDO ZÚÑIGA, Olga. Una derrota británica... Op. cit., p. 116.
} 
desde fines del siglo XVII encaminarían sus hombres en reforzar el cuidado y las guardias según las órdenes del gobernador de "[...] estar prontos a marchar al primer tiro de cañón" e impedir que el enemigo penetrase por dicho punto. Asimismo, las compañías de Jiguaní estaban llamadas para asistir a la ciudad de Santiago de Cuba en caso de cualquier amenaza que perturbase el equilibrio de la soberanía hispana en la región. De esta forma, se llegarían a organizar unos mil cincuenta y nueve efectivos -hombres de tropas (350) y milicianos (700)-, con el objetivo de asegurar las principales defensas de la plaza de $\mathrm{Cuba}^{18}$.

Para el mantenimiento diario de los combatientes, se destinaría el pago de un real diario, junto con raciones de tasajo, casabe, miel y aguardiente que no podrían ser respaldados por las arcas reales, al encontrarse arruinadas por no recibirse el situado desde hacía tres años ${ }^{19}$. En arreglo, el gobernador Cajigal solicitaría un préstamo de los representantes más acaudalados del patriciado criollo, apelando a sus intereses económicos por mantener la paz y la seguridad de sus operaciones comerciales y propiedades, asegurándoles que una vez que se recibiesen los fondos del situado, procedentes desde Nueva España, se les devolverían con creces tales favores, y, "... respecto a de que sería uno de los mayores servicios que podrán hacer a S.M. los colocaría en su real noticia, para que a proporción del que cada uno se supiese merecer la benignidad del rey, lo atendiese y honrare" ${ }^{20}$.

Una vez más la Corona pondría de manifiesto su política, en torno a los costes de mantener tan elevada cantidad de hombres mientras durasen las operaciones defensivas, de suma importancia para el equilibrio de la soberanía española. No obstante, del apoyo económico de numerosos hacendados, las cifras demandadas en tan compleja empresa no serán suficientes para el mantenimiento diario de todas las compañías retenidas en la localidad. Como solución inmediata se procedería a acuñar una moneda de cobre, en reales de a ocho y de cuartos, con los auxilios de una ceca instalada en las bóvedas del castillo de San Francisco, en el centro de la ciudad.

A partir del capital obtenido en la circulación de tales caudales, se facilitaría el sostenimiento de la ciudad mientras transcurriese la coacción inglesa ${ }^{21}$.Sin duda alguna, las medidas y prevenciones adoptadas durante el mandato del gobernador Francisco Cajigal de la Vega, tendrían un gran impacto en proveer a la ciudad de una infraestructura defensiva viable a partir de los recursos locales disponibles, que permitiese hacer frente a tan poderoso enemigo, y asegurar los víveres indispensables para el consumo y sostenimiento de las tropas y milicias en el sitio.

En medio de las precauciones y empeños de las autoridades coloniales, en la mañana del 20 de julio de 1741, Vernon y su contingente desembarcarían por la

\footnotetext{
${ }^{18}$ Ibídem, p. 137.

${ }^{19}$ MARRERO, Leví. Cuba economía... Op. cit., t. IV, p. 171.

20 Archivo General de Indias (en adelante AGI), Santo Domingo, 1203, n. 26. El gobernador de Santiago de Cuba al rey sobre los planes defensivos de la ciudad ante la amenaza británica. Cuba, 20 de febrero de 1741.

${ }^{21}$ PEZUELA, Jacobo. Historia de la isla de Cuba. T. II. Madrid: Imprenta Carlos Bailly-Bailliere, 1868, p. 373.
} 
bahía de Guantánamo, nombrándola bajo el nombre de Cumberland en honor al hijo del monarca Jorge II-. El objetivo de su expedición estaría centrado en reconocer el terreno y avanzar hacia la ciudad de Santiago de Cuba teniendo como refuerzo la flota, y de esta manera, efectuar el ataque de manera simultánea hasta conseguir desestabilizar el proyecto defensivo concebido por las autoridades españolas.

\section{Refuerzos y defensa}

Tras la llegada inglesa a suelo cubano, las realidades del clima tropical y la mala alimentación de sus tropas influirían en el descontento de sus hombres, y ocasionarían numerosas bajas por enfermedades desde el primer momento. No obstante, cejados en el empeño de sus dirigentes en avanzar hacia la urbe suroriental pretenderán el éxito de su cometido en la rapidez de sus acciones; y con arreglo a ello entenderán que tal como un siglo atrás los franceses habrían conseguido el territorio de Saint-Domingue, a partir de la ocupación de una parte de la isla, en su caso la nueva colonia inglesa libraría a los comerciantes británicos del peligroso corso español, y les dejaría libre para la navegación el Canal de los Vientos ${ }^{22}$.

Unido a la actitud defensiva de las fuerzas británicas, desde la llegada de Vernon a las cercanías de la localidad de Tiguabos, el gobernador Cajigal estimaría pertinente que el capitán y dueño del Hato de Guantánamo Pedro Hornedo, con alrededor de cuarenta hombres a su cargo entre negros, mulatos e indios, hostigarán con machetes y lanzas al enemigo, con el fin de sembrar el terror en las filas inglesas, y demostrar la ferocidad de las tropas cubanas en el combate cuerpo a cuerpo ${ }^{23}$.

Ante tales maniobras, la reacción inglesa no demoraría en distribuir manifiestos a la población local, especialmente indicados a los negros, mulatos e indios, expresándoles sus intenciones y condiciones:

"[...] serán libertados de los crecidos impuestos, alcabalas, derechos, prohibiciones y demás opresiones, que al presente padecen, de la naturaleza, y forma de gobierno establecido en las Indias españolas; y en particular los indios serán libertados de los reales tributos, y servicios, a que han estado sujetos. Tendrán el privilegio, y derecho de comerciar en derechura a la Gran Bretaña, y a todas las colonias británicas en la América, y en fin, en todos los eventos, y por todos respetos serán atendidos, socorridos, favorecidos y tratados, como los naturales de la Gran Bretaña"24.

Si prestamos especial atención los factores escogidos para hacer valer el conjunto de sus promesas, entenderemos la connotación revolucionaria perseguida por el mando británico con tales sugerencias, que sobretodo nos advierte un profundo conocimiento de la realidad social del espacio cubano. A partir de las

\footnotetext{
${ }^{22}$ MARRERO, Leví. Cuba economía... Op. cit., t. IV, p. 93.

${ }^{23}$ AGI, Santo Domingo, 364. Diario de lo ocurrido en Santiago de Cuba desde la primera noticia ante la intentada invasión por los ingleses. Cuba, julio-diciembre, 1741.

${ }_{24} \mathrm{AGI}$, Santo Domingo, 1203. Manifiesto del gobernador inglés Don Thomas Wentworth a la población de Cuba. Cuba, 25 de octubre de 1741.
} 
informaciones facilitadas a Vernon por varios prisioneros e informantes, quienes le confirmarían que los ingleses serían bien recibidos apelando al malestar de la población ante el predominio de unos pocos ricos, "[...] que ejercían su arbitrio poder sobre una multitud de gente pobre, que sin el recurso de leyes que les aliviasen de tan inhumana y antinatural conducta, llevaban una vida de debilidad y ocio"25.

La convocatoria se produciría en una coyuntura estratégica, donde las informaciones de los refuerzos defensivos con las compañías de milicias de los pueblos de indios de Los Caneyes, Jiguaní, y los negros cobreros de Santiago del Prado causaban grandes trastornos a la estrategia defensiva de Vernon ${ }^{26}$. En este sentido, el objetivo no sería cumplido, y al contrario del efecto esperado de sumisión y vasallaje, el conjunto de tropas populares comprometidas en la lucha retomaría con un mayor ímpetu la ofensiva contra los invasores. Como estímulo a sus actitudes, el gobernador Cajigal les reafirmaría su pleno apoyo moral, y les permitirá la incautación y posesión de todos los recursos que despojasen al enemigo en la batalla $^{27}$. Entendemos que la posición defensiva adoptada por los indios respondería a una dinámica de garantía de sus derechos, y a su vez, como reafirmación de su fiel vasallaje a los intereses de la Corona española.

\footnotetext{
${ }^{25}$ MARRERO, Leví. Cuba economía... Op. cit., t. IV, p. 104.

${ }^{26}$ DÍAZ, María Elena. The Virgin, the King and the Royals Slaves of El Cobre. Stanford University Press, 2002, p. 89.

${ }^{27}$ PORTUONDO ZÚÑIGA, Olga. Una derrota británica... Op. cit., p. 141.
} 


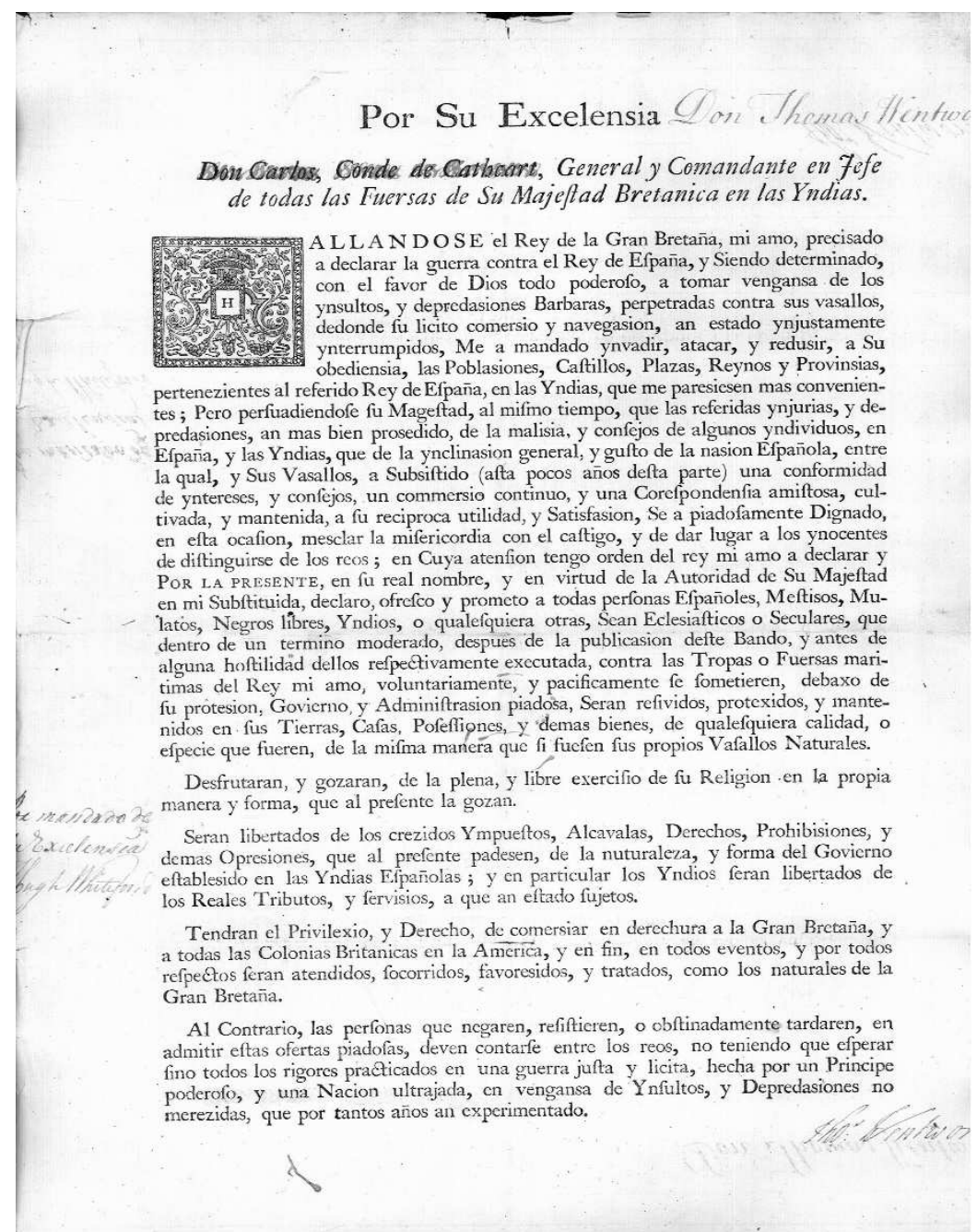

Fig. 2: Manifiesto del gobernador inglés Don Thomas Wentworth a la población de Cuba durante las acciones del sitio a Santiago de Cuba (1741). Fuente: Archivo General de Indias, Santo Domingo, 1203.

En medio de tal coyuntura defensiva, donde el reclamo inglés sería interpretado como el de unos habilidosos enemigos, que trastocaban la estabilidad política y económica del territorio suroriental, todos sus habitantes y vecinos, de conjunto con las autoridades hispanas, se volcarían en hacer frente a las hostilidades de tan poderoso adversario. En palabras de Portuondo Zúñiga, "el sentimiento de amor y apego a la patria local jugaría un rol determinante en impulsar el respaldo de los grupos de castas, que armados con lanzas y machetes harían frente a un invasor con tropas mayores y mejor pertrechadas" ${ }^{\prime 28}$.

Una vez los británicos patenticen el rotundo fracaso de sus planes subversivos, lanzarán abiertamente su ofensiva a la ciudad de Santiago de Cuba, previniendo forzar por asalto las baterías bajas del castillo del Morro y La Estrella, de conjunto con el refuerzo de la flota, y de esta forma, ejecutar un ataque por mar y tierra. Ante tales propósitos, los movimientos del gobernador Cajigal de la Vega no se harían demorar, tomando en cuenta que la rapidez de sus acciones y el aprovechamiento

\footnotetext{
${ }^{28}$ Ibídem, p. 162.
} 
de la destreza de sus milicianos en el conocimiento del terreno eran sus principales ventajas sobre el enemigo.

Siguiendo tales consideraciones, se dispondrán los trabajos de reforzamiento de la artillería del castillo del Morro con cuatro cañones de tres libras de bala (unos 9 $\mathrm{cm}$ ), de conjunto con tres compañías de milicias para los trabajos. Junto a ello, se tomaría la determinación de que la milicia de San Luis de los Caneyes se retirase a su pueblo, en el intento de reforzar los caminos que conducían a Guantánamo. Una vez comprobado el cambio de rumbo a sotavento de las fuerzas inglesas, se mandaría a retornar a la compañía del Caney a sus puestos de Juragua, de conjunto con los refuerzos llegados desde Bayamo y Holguín ${ }^{29}$.

La descripción del aspecto y el armamento de las tropas cubanas refieren que los milicianos vestirían un uniforme de casacas con faldetas, zapatos de vaqueta altos, sombrero de yarey con cinta o escarapela azul y blanca, correaje de piel amarilla, y una mochila de aspecto rústico. Debían llevar, asimismo, la pólvora y balas en depósitos, hechos de cuero de res con fondos y tapas de cedro, pendientes de correas. Las tropas de infantería, usarían fusil largo y pesado, de fabricación española, calibre de dieciocho libras, con un alcance medio de trescientas varas, todo ello acompañado por bayoneta, y un sable corto y ancho. Por su parte, los de caballería, compartirían igual uniforme, pero la cinta del sombrero blanca y amarilla, y lanza, pistola y sable más largo que el de los infantes ${ }^{30}$. La táctica estratégica del gobernador Cajigal cumpliría con el objetivo de perfeccionar todas las defensas, y evitar cualquier error que pudiese ser aprovechado por el enemigo para perpetuar su ventaja.

Finalmente, y tras varios meses de combate, el 25 de agosto de 1741, llegarían los ansiados y prometidos refuerzos enviados desde La Habana por el capitán general, consistentes en doscientos hombres en diecisiete embarcaciones, cien quintales de pólvora, doscientos fusiles, siete quintales de balas y treinta mil pesos en situados para sufragar los gastos de las operaciones y el pago de las tropas y milicias $^{31}$. No obstante, del importante refuerzo, para evitar cualquier agresión inesperada era necesario una acertada planificación que consiguiera adelantar todos los movimientos de Vernon. Frente a ello, el mejor recurso era la posibilidad de desplegar las compañías de milicias criollas con amplios conocimientos del terreno, y sobradas habilidades en el manejo de los machetes y lanzas. Precisamente, el mayor temor de los invasores acostumbrados a la estrategia de combate en sitios despejados.

Asimismo, un importante recurso naval utilizado lo representarían los corsarios particulares, que encargados de custodiar las rutas marítimas de interés para la Corona hispana, obligarían al enemigo a extender sus fuerzas navales hasta un límite crítico que pondrá en alerta la seguridad de sus tropas en tierra, al forzar a las naves británicos a expandir su área de acción hacia la zona calificada como

\footnotetext{
${ }^{29}$ AGI, Santo Domingo, 364. Diario de lo ocurrido en Santiago de Cuba desde la primera noticia ante la intentada invasión por los ingleses. Cuba, julio-diciembre, 1741.

${ }^{30}$ PEZUELA, Jacobo. Historia de... Op. cit., t. II, p. 382.

${ }^{31}$ MARRERO, Leví. Cuba economía... Op. cit., t. IV, pp. 102-110.
} 
"peligrosa", en latitudes lejanas hacia el norte de las Bermudas ${ }^{32}$.

Con la entrada de la compañía de naturales de Jiguaní, conformada por cincuenta y nueve hombres y sus oficiales, de conjunto con las de San Luis del Caney, se procedería a reconocer la posición y estado de los invasores, llevando la particular instrucción de no malograr las ocasiones de escarmentar, y traer algunos prisioneros para indagar sus intenciones. Finalmente, gracias a las habilidades de los indios del Caney se conseguiría apresar al final cinco negros esclavos, que confesarían los planes del enemigo, a la espera del refuerzo de una escuadra para atacar por mar y tierra la plaza de $\mathrm{Cuba}^{33}$.

Ante tales noticias, el gobernador Cajigal no demoraría en solicitar la asistencia del experimentado capitán Pedro de Hornedo, quien acudiría al llamado, con cerca de ciento cuarenta hombres de la jurisdicción de Guantánamo, en el intento de perturbar las operaciones del enemigo y obtener toda la información de sus movimientos ${ }^{34}$. La táctica manejada, de inquietar a todas horas con pequeñas partidas de negros e indios al adversario, motivaría que el curso de las acciones fuese favorable al bando cubano. La estrategia de desgaste ocasionaría serias dificultades al mando británico, y contribuiría en gran medida a la desmoralización de sus tropas, frente a un adversario que irregular y mal armado conseguiría arrebatarle numerosas victorias ${ }^{35}$.

Llegado el punto, donde los objetivos perseguidos por las autoridades británicas se verán frustrados una y otra vez por la rápida intervención de las fuerzas criollas, al contrarrestar su avance hacia la capital departamental por tierra, no abandonarán el empeño en atacar la ciudad por vía marítima, y de esta forma, sopesar un posible desembarco en cualquiera de sus puntos en Guantánamo ${ }^{36}$. Ante tales tentativas, Cajigal decidiría que entrasen de refuerzo las compañías de Holguín y de Jiguaní, esta última con alrededor de sesenta y siete hombres y oficiales, con la intención de fortalecer los trabajos en el castillo del Morro ante la incontenible deserción de los negros esclavos encargados de su defensa; y a su vez, dispondría el envío de dos mil balas de fusil al puesto de Juraguasito ante la amenaza de un inminente ataque $^{37}$.

No obstante, a inicios de noviembre de 1741, tendría lugar la máxima tensión en el mando de la expedición británica entre Vernon y Wentworth; en medio de la profunda depresión de sus tropas tras las continuas derrotas y las numerosas bajas,

${ }^{32}$ GARCÍA DEL PINO, César. Corsarios, piratas y Santiago de Cuba. La Habana: Editorial de Ciencias Sociales, 2009, pp. 96-97.

${ }_{33}$ AGI, Santo Domingo, 364. Diario de lo ocurrido en Santiago de Cuba desde la primera noticia ante la intentada invasión por los ingleses. Cuba, julio-diciembre, 1741.

${ }^{34}$ AGI, Santo Domingo, 1203, n. 15. El gobernador Francisco Cajigal expone al rey las noticias recibidas desde Guantánamo. Guantánamo, 25 de octubre de 1741.

${ }_{35}$ KUETHE, Allan J. y KENNETH J. Andrien. El mundo atlántico español durante el siglo XVIII. Guerra y reformas borbónicas, 1713-1796. Bogotá: Editorial Universidad del Rosario; Banco de la República, 2018, p. 153.

${ }^{36}$ PORTUONDO ZÚÑIGA, Olga. Una derrota británica... Op. cit., p. 158.

${ }^{37} \mathrm{AGI}$, Santo Domingo, 364. Diario de lo ocurrido en Santiago de Cuba desde la primera noticia ante la intentada invasión por los ingleses. Cuba, julio-diciembre, 1741. 
que catalizarían la decisión final de abandonar el sitio de Guantánamo. Al tomar tan importante determinación, se daba reconocimiento oficial al fracaso de la misión en el suroriente cubano, y se asumía por las autoridades británicas su derrota, ante la incapacidad de reactivar las defensas, y la demora de nuevos refuerzos desde el resto de dominios británicos. Tras varios meses de intenso batallar se quedaban sin provisiones, lo que unido al azote de enfermedades tropicales como la fiebre amarilla y las desavenencias internas hacían insostenible su permanencia en la jurisdicción de Cuba ${ }^{38}$.

Bajo tales circunstancias, entre el 26-27 de noviembre de 1741, comenzarían a salir de la bahía de Guantánamo los primeros buques británicos, que transportarían los heridos y enfermos hacia Jamaica. Luego de más de cinco meses de intenso asedio a la ciudad de Santiago de Cuba, donde casi dos tercios del total de hombres habían perecido, no se habían cumplido los pronósticos de ocupar la isla de Cuba, y tomar el puerto de La Habana. Al decir de Jacobo de la Pezuela, "...la multitud de sepulcros y cadáveres hallados en su campo, los fardos y pertrechos abandonados allí por todas partes, terminarían de explicar la situación en que la abandonaban"39.

Mientras tanto, en el bando hispano, el gobernador Cajigal de la Vega no pondría frenos al agresor para su retirada, aunque no confiaría en sus movimientos, y ordenará a sus hombres estar alertas en los distintos puntos de la costa que fuesen vulnerables a un último intento por forzar las defensas de la ciudad.

Como consecuencia directa de la derrota sufrida por Vernon y su escuadra, el parlamento inglés cesaría de su cargo al primer ministro Robert Walpole, en diciembre de 1741, al atribuirle acusaciones apoyadas en el fracaso de la expedición británica en el Caribe hispano ${ }^{40}$. Los profundos intereses económicos que habían iniciado el conflicto armado entre ambas potencias europeas, tendrían una especial repercusión en que IOS comerciantes ingleses reconociesen que sus mercados no estaban a buen resguardo, y, en consecuencia, solicitasen a Londres medidas más eficaces $^{41}$.

\section{Balance y experiencias tras la victoria}

Una vez los ingleses abandonen definitivamente el territorio cubano, las autoridades de Santiago de Cuba no demorarían en remitir un pormenorizado informe a la Corona del levantamiento del sitio a la ciudad. Así, en diciembre de 1741, remitirían un análisis de la victoria conseguida frente al poderoso rival inglés, prestando un especial reconocimiento a los distintos factores humanos y estratégicos que habían permitido conseguir tan importante resultado ${ }^{42}$. Con relación a la labor desarrollada por el conjunto de las milicias destacarían, "[...] los oficiales y

${ }^{38}$ Cfr. MCNEILL, John Robert. Mosquito Empires: Ecology and War in the Greater Caribbean, 16201914. Cambridge: Cambridge University Press, 2010.

${ }^{39}$ PEZUELA, Jacobo. Historia de... Op. cit., t. II, p. 386.

${ }^{40}$ PORTUONDO ZÚÑIGA, Olga. Una derrota británica... Op. cit., p. 164.

${ }^{41}$ HARDING, Richard. America, the War of 1739-1748 and the development of British global power. Journal of Maritime Research. 2004, vol. 6, n. 1, pp. 1-20.

42 AGI, Santo Domingo, 364. El gobernador Francisco Cajigal de la Vega da cuenta sobre el levantamiento del sitio a Santiago de Cuba. Santiago de Cuba, 2 de diciembre de 1741. 
capitanes, de infantería y milicias han hecho su deber con empeño, [...] han acudido prontamente a los rebatos, y ejecutado las órdenes con ciega obediencia" ${ }^{\prime 3}$. En este sentido, cabe señalar que el importante desempeño de las milicias de los pueblos de indios de Los Caneyes y Jiguaní sería ampliamente documentado a lo largo de la relación de sucesos, todo un reconocimiento formal y moral al conjunto de naturales que, abandonando sus moradas se habían puesto al servicio de la Corona, con el objetivo de salvaguardar la soberanía hispana de los intereses foráneos. Por vez primera, y abiertamente, los mandos locales declararían al gobierno central las cifras de indios o naturales implicados en la contienda bélica. Es decir, que sus participaciones no representaban esa "minoría" olvidada e inútil que muchas veces intentarían transfigurar obispos, curas y gobernadores en sus comunicaciones oficiales.

La práctica demostraría que la estrategia articulada a partir del reforzamiento defensivo con las milicias locales y el apoyo económico de la oligarquía criolla, significaría la victoria sobre un rival tan fuerte y bien pertrechado. Y así darían fe en su declaración a la Corona:

"[...] a propósito de mis débiles fuerzas, no les ha quedado que hacer, manteniendo constante el honor de las armas de V.M., dejando vergonzosos a las de los contrarios en medio del superior número con que las han medido, siendo para su dominante altiva soberbia, un borrón que padecerán irreparable en este y estos reinos" 44 .

Sin duda alguna, el triunfo conseguido por el gobernador Francisco Cajigal de la Vega pondría en el tintero la enorme valía defensiva del territorio suroriental, y en especial manifestaría la profunda lealtad de sus vasallos a los intereses oficiales. La participación activa y fundamental de los distintos cuerpos de milicias vendría a significar un hito dentro de la estrategia colonial al permitirse a grupos sociales como indios, negros y pardos el ejercer un papel destacado, y demostrar el apego a su patria local.

Las acciones y combates desarrollados a los largo de los meses de asedio y sitio a la ciudad de Santiago de Cuba, pondrían en evidencia la necesidad y utilidad en adiestrar en las técnicas modernas de guerra a los distintos batallones de milicias, para de esta forma acercarles al nivel defensivo de las tropas regulares, y conseguir un defensa más eficaz de la plaza de $\mathrm{Cuba}^{45}$. Quedaba demostrado que el adiestramiento de estos grupos, lejos de significar una amenaza a la estabilidad del dominio colonial, garantizarían en buena medida la conservación del poder de España en América frente a los intereses del resto de imperios europeos.

Como premio a sus fieles servicios, el gobernador departamental Cajigal de la Vega recibiría numerosos reconocimientos que le valdrían un lugar destacado en el cuadro americano. ${ }^{46} \mathrm{La}$ imponente victoria conseguida desde la plaza de Cuba

\footnotetext{
${ }^{43}$ Ibídem.

44 lbídem.

45 PORTUONDO ZÚÑIGA, Olga. Una derrota británica... Op. cit., p. 184.

${ }^{46}$ En el transcurso de 1742 será nombrado como capitán general de Caracas, luego como mariscal de campo junto con el reconocimiento del Real y Supremo Consejo de Guerra. En 1747 sería
} 
redundaría en los años posteriores en un mayor reconocimiento oficial al territorio, ratificándole a la ciudad el título de "Muy Noble y Muy Leal", así como numerosos beneficios económicos para contentar a su patriciado criollo, especialmente en la supresión de impuestos como los del comercio marítimo de carne salada y pescados $^{47}$.

Las circunstancias económicas serian favorables para continuar con el perfeccionamiento de sus principales baluartes, ante la afluencia y mejora del situado. En particular, se darían pasos en la adopción de un plan estratégico de poblamiento para la bahía de Guantánamo, con el objetivo de asegurar las defensas de la zona, a fin de evitar que acciones como la ocurrida entre 1739-1741, se repitiese en nuevos escenarios aprovechando la vulnerabilidad de la región ${ }^{48}$.

De las experiencias recibidas durante los meses de combate, el mando colonial apreciaría el potencial defensivo de los cuerpos de milicias convocadas, y en especial, los grupos de Los Caneyes y Jiguaní, consolidarían un protagonismo fundamental, y serian legitimados por las autoridades locales como una fuerza de gran impacto ante cualquier incidente o amenaza.

A partir de la supuesta bonanza económica, la producción de bienes en la zona oriental de la isla alcanzaría cifras sin precedentes, y motivaría la introducción de elevadas cantidades de negros esclavos para hacer frente a la demanda del mercado de valores de cambio. No obstante, según refieren las actas capitulares de la ciudad durante el periodo comprendido entre 1742-1747, la crisis en el suministro de alimentos como plátano, frijoles y casabe acentuaría la pobreza de quienes constituían los estamentos más bajos de la sociedad colonial, dígase los indios, negros y pardos libres ${ }^{49}$.

En este sentido, no sería de extrañar que la alta disposición en las milicias por estos años, respondiera a un criterio de subsistencia de muchas familias imposibilitadas de percibir otro sustento económico. Muchas de las denuncias tomadas en valor por estos años del cura de la parroquia de San Luis de los Caneyes nos retratan un panorama desolador para buena parte de los naturales, que desprovistos de buena parte de sus terrenos, debido a la geofagia de la oligarquía local, se declararían en bancarrota al no poder pagar la comunidad ni los costes del sacristán mayor, "por ser la parroquia más pobre de toda la cristiandad" 50 .

Tanto las necesidades del pueblo, como la propia coyuntura política para la defensa, ejercerían de marco propicio para que las milicias se convirtiesen en oficio demandado por sus habitantes, valiéndose de los conocimientos y prácticas

finalmente designado como capitán general de la isla de Cuba; vid. PEZUELA, Jacobo. Historia de... Op. cit., t. II, pp. 387-388.

${ }_{47}$ PORTUONDO ZÚÑIGA, Olga. El Departamento Oriental. 1510-1868: dos temas de historia económica. Santiago de Cuba: Editorial Santiago, 2012, p. 36.

${ }^{48}$ Cfr. HERNÁNDEZ LÓPEZ, Ignacio. La defensa... Op. cit.

${ }^{49}$ Archivo Histórico Provincial de Santiago de Cuba, Actas capitulares, n. 3, 28 de enero de 1743, f. 211-212 y f. 272v.

${ }^{50}$ MARRERO, Leví. Cuba economía... Op. cit., t. IV, p. 12. 
ancestrales desarrolladas desde tiempo inmemoriales ${ }^{51}$. La participación de los indios en la defensa, lejos de significar una distinción, contribuiría en perpetuar un modelo de sociedad colonial, que de esta manera ratificaría su diferenciación a nivel corporativo, amparado en su pasado histórico.

De esta manera, cuando a inicios de 1747, la amenaza de una nueva incursión inglesa asome viejos fantasmas sobre la jurisdicción oriental, su entonces gobernador Alonso de Arcos y Moreno, recibiría rigurosas disposiciones de su antecesor Francisco Cajigal de la Vega, ahora capitán general de la isla, bajo los términos de:

"[...] De las dos compañías de Jiguaní se puede prontamente sacar un lúcido piquete, y ser también relevado en el caso preciso pues debemos considerar los tiempos y que no falte sus manutenciones, atención muy precisa para arreglar las cosas de forma que el servicio se haga, los paisanos sirvan y los puestos se mantengan con vigilancia midiendo las cosas a proporción de las ocurrencias y fondos para la subsistencia de los que quedaren empleados que deberán ser lo que basten para dar lugar a poder ser reforzados con presteza como lo serán con las milicias de la ciudad, Cobre y Caney que quedan de reten"52.

Apoyándose en la experiencia combativa de 1741, recomendaría el apoyo combativo a los distintos cuerpos de milicias, y la disposición de un plan de defensa encaminado en el manejo de los recursos locales, incluidos los corsarios criollos, para proteger las costas y atacar las embarcaciones enemigas. Las circunstancias estratégicas de la región suroriental habían mejorado notablemente en el período comprendido entre (1742-1748), gracias a su papel como puerto intermediario en el Caribe, y la afluencia de los caudales del situado que servirían en el pago de las tropas de refuerzo y las mejoras defensivas de su litoral costero.

Todo ello ejercería de marco propicio para que el gobernador De Arcos y Moreno, en un intento de sumar méritos ante la Corona, trazase un plan encaminado a recuperar Jamaica con el fiel apoyo de los guardacostas locales, jactándose de las numerosas presas a los ingleses ${ }^{53}$. En la articulación de su estrategia ilustraría al monarca que, "con seis navíos de guerra de la escuadra que hay en la Habana, bien tripulados, y tres mil hombres entre tropa veterana, y milicias, creo serían bastantes para cantar la victoria" ${ }^{54}$.

Como vendría siendo habitual, las fuerzas de Los Caneyes y Jiguaní, serían convocadas, y en esta ocasión se darían precisas instrucciones que no se les entregasen armas de fuego hasta tanto no estuviesen en el terreno de combate, previniendo un mejor control sobre las escopetas y fusiles. Si bien eran necesarios y

${ }^{51}$ Cfr. RUIZ IBÁÑEZ, Javier (ed.). Las milicias del rey de España. Ciudad de México: Fondo de Cultura Económica, 2009, p. 12.

${ }_{52}$ ANC, Correspondencia de los capitanes generales, leg.1, exp.10. Carta de Francisco Cajigal de la Vega, capitán general de la isla de Cuba, a Alonso de Arcos y Moreno, gobernador de Cuba. La Habana, 30 de abril de 1748.

${ }^{53}$ GARCÍA DEL PINO, César. Corsarios... Op. cit., p. 101.

${ }^{54} \mathrm{AGI}$, Santo Domingo, 1202. El gobernador de Cuba D. Alonso de Arcos y Moreno propone medios para recobrar y rendir la isla de Jamaica, sin coste de la real hacienda, y con casi evidente modo de conseguirlo. Santiago de Cuba, 26 de octubre de 1747. 
valorados para la defensa, representarían un colectivo que era necesario mantenerles bajo atención, de acuerdo a las particularidades del orden social y la disciplina implícita bajo filas ${ }^{55}$.

De acuerdo a la previsiones, la reacción británica no se haría demorar, y el 8 de abril de 1748, el almirante Charles Knowles al frente de una portentosa escuadra formada por ocho barcos de guerra de línea, dos fragatas, tres balandras y más de trescientos soldados avanzarían nuevamente hacia la bahía de Santiago de Cuba con el objetivo de escarmentar los impulsos de la base corsaria y, en la misma medida, castigar la derrota de Vernon demostrando la superioridad de las fuerzas inglesa atacando los puntos vulnerables de la bahía santiaguera ${ }^{56}$.

Como bien señalaría Pezuela, "lejos de conseguir un desagravio, hallarán en Santiago un nuevo descalabro"57, donde la plaza ante la fuerte y organizada resistencia criolla lejos de ceder al enemigo según lo ocurrido en 1662 con Myngsresistió el asalto. Las estrategias manejadas serian apuntadas por el gobernador general Cajigal de la Vega quien opinará que:

"con la fuerza del Morro y La Estrella, no se necesitaba de las pruebas que han dado para estar con la más segura confianza de que harán respetable esa entrada, la que será más impenetrable siempre que se construya mi proyecto da batería en el paredón, de formidable condiciones habiendo artillería a lo menos de una distancia de esa plaza $[\ldots]^{\prime \prime 58}$.

Advertido tal escenario, al arrimarse los navíos ingleses a tiro de fusil de las fortalezas serán rechazados por un volcán de metralla y balas rasas al estar las baterías tan prevenidas, junto con un despliegue de las fuerzas de milicias de Santiago de Cuba, Santiago del Prado, San Luis de Los Caneyes, Jiguaní, Bayamo y Puerto Príncipe en los puntos más vulnerables al desembarco, como eran Aguadores o Jurágua ${ }^{59}$.

La estrategia seguida por el gobernador desde los primeros momentos y basada en la distribución de las milicias entre los puntos fortificados, de conjunto con el refuerzo de la artillería, serían elementos decisivos para contrarrestar el avance del enemigo a la ciudad y en conseguir asestarle notables pérdidas y numerosas bajas, que provocarían que Knowles resolviese retirar sus embarcaciones de regreso a Jamaica ante la inminente derrota de la expedición.

En abril de 1748, se firmarían los acuerdos de paz entre las coronas de Gran Bretaña y España, y se pondría fin a las hostilidades en el ámbito caribeño. No obstante, de la derrota inglesa, las experiencias y el conocimiento adquirido sobre el

\footnotetext{
${ }^{55}$ ANC, Correspondencia de los capitanes generales, leg. 1, exp.8. Carta de Francisco Cajigal de la Vega al gobernador de Cuba Alonso de Arcos y Moreno. La Habana, 21 de abril de 1748.

${ }^{56}$ PORTUONDO ZÚÑIGA, Olga. Una derrota británica... Op. cit., pp. 180-181.

${ }^{57}$ PEZUELA, Jacobo. Historia de... Op. cit., t. II, p. 416.

${ }^{58}$ ANC, Correspondencia de los capitanes generales, leg. 1, exp.10. Francisco Cajigal de la Vega a Alonso de Arcos y Moreno. La Habana, 30 de abril de 1748.

${ }^{59}$ AGI, Santo Domingo, 1203, n. 26. Diario de lo ocurrido en Santiago de Cuba con la escuadra del Almirante Knowles. Santiago de Cuba, 18 de noviembre de 1748.
} 
espacio cubano serian de gran ayuda en perfeccionar sus ataques, y ello quedaría patentizado cuando a más de una década retomen con energías el proyecto de asaltar la isla de Cuba, y en especial, el importante el enclave de La Habana.

Un elemento distintivo de la contienda lo representaría, sin duda alguna, la participación, y la naturaleza social de los diferentes actores involucrados directa e indirectamente en las acciones defensivas, con representación de diversos intereses ${ }^{60}$. Sus asistencias se justificarían en un acto de lealtad de los criollos de la jurisdicción y de amor a la patria chica ${ }^{61}$. Todo ello sería muy bien aprovechado por sus autoridades y la oligarquía local como una reafirmación en su vasallaje a los intereses oficiales. La fiabilidad y el alistamiento de las milicias marcarían un punto de partida para su reconocimiento oficial, en respuesta a la efectividad demostrada sobrepasando los efectos formales y el deber militar.

\section{Conclusiones}

Con el advenimiento del siglo XVIII, y a partir de la instauración borbónica en España, el puerto de Santiago de Cuba, cobraría una puntual importancia en su condición de punto intermedio del comercio esclavista antillano, y como base corsaria criolla, de interés oficial en el reconocimiento y mantenimiento de agentes particulares que servirán en la protección y el hostigamiento a los enemigos naturales de la Corona. En este contexto, el revés sufrido por las fuerzas británicas a manos de los criollos santiagueros daría fin a la conocida "Guerra de la Oreja de Jenkins", donde los conflictos comerciales entre las naciones europeas habían sido trasladados al espacio Caribe. Las guerras coloniales y las disputas por el control de las rutas comerciales atlánticas tendrían como consecuencia directa que Inglaterra lanzase una ofensiva directa en el Caribe hispano, como paso estratégico en la apertura de nuevos mercados y el interés en afianzarse económica y políticamente por todo el continente americano.

Por lo que se refiere, al papel desempeñado por las milicias populares o auxiliares, como elemento de primer orden para la defensa local, se mostraría abiertamente la diligencia de los grupos criollos, que patentizarían su validez dentro del escenario regional. En particular, las compañías organizadas en los pueblos de indios de San Luis de Los Caneyes y San Pablo de Jiguaní, que vendrían a corroborar la utilidad con que serían relacionadas tales comunidades. En el ejercicio de salvaguardar el territorio costero cubano, podemos evidenciar un fenómeno subyacente donde la apuesta por fortalecer los vínculos con la Corona permitiría un reconocimiento a los indígenas en sus habilidades ancestrales, y les identificaría con el espacio geográfico a proteger.

\section{Fuentes Primarias}

Archivo General de Indias (AGI), Sevilla, España.

Archivo Histórico Provincial de Santiago de Cuba (AHPSC), Santiago de Cuba,

\footnotetext{
${ }^{60}$ DÍAZ, María Elena. The Virgin... Op. cit., pp. 90-91.

${ }^{61}$ PORTUONDO ZÚÑIIGA, Olga. Una derrota británica... Op. cit., p. 185.
} 
Cuba.

Archivo Nacional de Cuba (ANC), La Habana, Cuba.

\section{Bibliografía}

AMOR MARTÍN, Francisco de Asís. Crónica del combate naval de La Habana de 1748. Naveg@mérica. Revista electrónica editada por la Asociación Española de Americanistas. 2018, n. 20.

BAUDOT MONROY, María (ed.). El Estado en Guerra. Expediciones navales españolas en el siglo XVIII. Madrid: Ediciones Polifemo, 2014.

BEAEZA MARTIN, Ascensión. Las argucias de la guerra: El gobernador Cajigal y el asedio inglés desde Guantánamo en 1741. Temas Americanistas. 2007, n. 19, pp. 50-69.

CERDÁ CRESPO, Jorge. Conflictos coloniales: la Guerra de los Nueve Años 17391748. Alicante: Servicio de Publicaciones de la Universidad de Alicante, 2010.

DÍAZ, María Elena. The Virgin, the King and the Royals Slaves of El Cobre. Stanford University Press, 2002.

GARCÍA DEL PINO, César. Corsarios, piratas y Santiago de Cuba. La Habana: Editorial de Ciencias Sociales, 2009.

HANSEN, Jonathan M. Guantánamo. An American History. Nueva York: Hill and Wang, 2011.

HARDING, Richard. Amphibious warfare in the eighteenth century. The British Expedition to the West Indies, 1740-1742. Woodbridge: Boydell \& Brewer Inc. 1991.

HARDING, Richard. America, the War of 1739-1748 and the development of British global power. Journal of Maritime Research. 2004, vol. 6, n. 1, pp. 1-20.

HERNÁNDEZ LÓPEZ, Ignacio. La defensa de Santiago de Cuba al ataque de Vernon de 1741: Principios de fortificación para la guerra en el Caribe. Anuario de Estudios Americanos. 2019, vol. 76, n. 1, pp. 177-207.

KUETHE, Allan J. y KENNETH J. Andrien. El mundo atlántico español durante el siglo XVIII. Guerra y reformas borbónicas, 1713-1796. Bogotá: Editorial Universidad del Rosario; Banco de la República, 2018.

MARRERO, Leví. Cuba economía y sociedad. Madrid: Editorial Playor, 1975.

MCNEILL, John Robert. Mosquito Empires: Ecology and War in the Greater Caribbean, 1620-1914. Cambridge: Cambridge University Press, 2010. 
PARES, Richard. War and Trade in the West Indies, 1739-1763. Londres: Oxford University, 1936.

PEZUELA, Jacobo. Historia de la isla de Cuba. Madrid: Imprenta Carlos BaillyBailliere, 1868.

PORTUONDO ZÚÑIGA, Olga. Santiago de Cuba desde su fundación hasta la guerra de los diez años. Santiago de Cuba: Editorial Oriente, 1989.

PORTUONDO ZÚÑIGA, Olga. El Departamento Oriental. 1510-1868: dos temas de historia económica. Santiago de Cuba: Editorial Santiago, 2012.

PORTUONDO ZÚÑIGA, Olga. Una derrota británica en Cuba. Santiago de Cuba: Editorial Oriente, 2015.

RIVAS IBAÑEZ, Ignacio. Mobilizing resources for war: The British and Spanish intelligence systems during the War of Jenkins' ear (1739-1744) [tesis doctoral inédita]. Londres: University College, 2008.

RUIZ IBÁÑ̃E, Javier (ed.). Las milicias del rey de España. Ciudad de México: Fondo de Cultura Económica, 2009.

ZAPATERO, Juan Manuel. La guerra del Caribe en el siglo XVIII. Madrid: Servicio Histórico Militar, 1990. 